\title{
Bone Crystal Maturation in Renal Osteodystrophy in Humans
}

\author{
James M. Burnell, Elizabeth Teubner, Jon E. Wergedal, and \\ DONALD J. ShERRARD \\ From the University of Washington, Department of Medicine, and the \\ Veterans Administration Hospital, Seattle, Washington 98195
}

A B S T R A C T Calcium, phosphorus, sodium, carbonate, magnesium, and hydroxyproline were measured in iliac crest biopsies of 22 normal volunteers and 24 selected patients with renal osteodystrophy. Histologic classification revealed that 10 were mildly abnormal, 8 osteomalacic, and 6 osteofibrotic. Bone density measurements were performed on an additional 12 normal, 11 mildly abnormal, 6 osteomalacic, and 10 osteofibrotic subjects. The results revealed an increase in magnesium and a decrease in carbonate apparent in the minimal and osteomalacic lesions and a much greater change in osteofibrosis. The bone density was decreased in patients with osteofibrosis. These observations would appear to be explained by postulation of an impairment of the normal maturational process of bone whereby there is an increase in amorphous calcium phosphate and a decrease in apatite crystal. The data suggest that the maturational defect is present as soon as any abnormality can be identified histologically, is present to the same degree in osteomalacia, and is most severe in osteofibrosis. In comparison of two sets of six patients matched for age and duration of dialysis, neither acidosis nor vitamin $D$ therapy appeared to influence the severity of the maturational defect.

\section{INTRODUCTION}

It has been demonstrated in rats that uremia results in a maturational defect in both collagen (1) and bone mineral (2). The failure to prevent this lesion by vitamin D therapy (2) has implied that this lesion was associated with secondary hyperparathyroidism or some as yet unidentified defect related to the accumulation of uremic toxins.

The present study identifies a decrease in bone carbonate and an increase in bone magnesium in all patients biopsied. These abnormalities are interpreted to be similar to the maturational defect found in rats. It

\footnotetext{
Received for publication 12 June 1973 and in revised
} form 20 August 1973. is most severe in osteofibrosis, where it is associated with decreased density and appears to be uninfluenced by the degree of acidosis or by vitamin D therapy.

\section{METHODS}

All patients had chronic renal disease of long standing; 22 of 24 had been on repetitive hemodialysis for from 2 mo to $5 \frac{1}{2}$ yr. Bone biopsies were taken $1 \mathrm{~cm}$ and $2 \mathrm{~cm}$ from the anterior superior iliac spine with an electric core drill $^{1}$ yielding a longitudinal biopsy approximately $0.4 \mathrm{~cm}$ in diameter and over $1 \mathrm{~cm}$ in length, with a cortical strip of varying depth at one end.

Each biopsy was sliced in half, the spicular portion being placed in $10 \%$ buffered formaldehyde solution for the histological study and the spicular-cortical half weighed immediately and placed in 1:1 petroleum-ethyl ether solution for chemical analysis. After fat extraction the latter bone core was dried to an air-stable weight. True density (weight per unit volume of bone and matrix only) was obtained by the volume displacement method with heptane (bp $98^{\circ}-99^{\circ} \mathrm{C}$ ) instead of water to prevent loss of carbonate and other soluble salts from the bone. The biopsy was attached to 6-0 silicon-coated silk suture, suspended, and weighed in the air, placed in heptane under vacuum until all trapped air was removed, and then resuspended, and weighed in heptane. True volume equals difference in weight per unit weight of heptane at ambient temperature. True density equals air-stable weight per unit true volume. Dry weight was obtained by heating to $100^{\circ} \mathrm{C}$ under vacuum for $12 \mathrm{~h}$, after which the sample was frozen with liquid $\mathrm{N}_{2}$, powdered, and dried to an air-stable weight for the chemical determinations. The yield was normally $15-25 \mathrm{mg}$. The bone density measurements were not performed in the original 24 patients, but subsequently on 12 normals and 27 patients with renal osteodystrophy. Classification of the biopsies from which density is reported was based on the same histologic criteria used for the original set.

By methods described before (3), bone sodium was determined by neutron activation, bone carbonate by direct manometric analysis, and the whole sample subsequently used for measurement of phosphorus by the Techinicon AutoAnalyzer (Technicon. Instruments Corp., Tarrytown, N. Y.), and $\mathrm{Ca}$ and $\mathrm{Mg}$ by regular atomic absorption spectroscopic methods.

\footnotetext{
${ }^{1}$ Myelotomiegerät, Institute F. Straumann, Waldenburg B.L., Switzerland.
} 
TABLE I

Histological Classification of Human Iliac Crest Biopsies

\begin{tabular}{|c|c|c|c|c|c|c|c|}
\hline \multirow{2}{*}{$\begin{array}{c}\text { Classification } \\
\quad(n)\end{array}$} & \multicolumn{3}{|c|}{ Total bone Perimeter } & \multirow{2}{*}{$\frac{\text { Total bone area }}{\begin{array}{c}\text { Mineralized } \\
\text { (osteoid) }\end{array}}$} & \multicolumn{3}{|c|}{ Bone formation } \\
\hline & Forming & Resorbing & Neutral & & $L_{F} *$ & $\mathbf{R}_{\text {BA }} \ddagger$ & $\mathbf{R}_{B F} \S$ \\
\hline & $\%$ & $\%$ & $\%$ & $\%$ & $\mathrm{~mm}^{2} / \mathrm{mm}^{3} \times 10^{-4}$ & $\mu m / d a y$ & $\mathrm{~mm}^{3} / \mathrm{mm}^{3} \times 10^{-8}$ \\
\hline \multirow[t]{2}{*}{ Normal (19) } & 18.16 & 4.03 & 77.80 & $94.31 \quad(5.69)$ & 0.52 & 0.31 & 1.50 \\
\hline & \pm 7.96 & \pm 1.98 & \pm 8.20 & \pm 7.72 & \pm 0.20 & \pm 0.08 & \pm 0.62 \\
\hline \multirow[t]{2}{*}{ Mild disease (10) } & 34.77 & 5.66 & 59.55 & $93.70 \quad(6.30)$ & 1.02 & 0.28 & 2.87 \\
\hline & \pm 9.90 & \pm 1.75 & \pm 10.57 & \pm 2.02 & \pm 0.25 & \pm 0.08 & \pm 1.13 \\
\hline$P$ vs. normal & $<0.001$ & $<0.05$ & $<0.001$ & N.S. & $<0.001$ & N.S. & $<0.001$ \\
\hline \multirow[t]{2}{*}{ Osteomalacic (8) } & 76.68 & 5.55 & 17.76 & $67.59(32.41)$ & 3.04 & 0.10 & 3.31 \\
\hline & \pm 9.80 & \pm 2.02 & \pm 9.30 & \pm 16.52 & \pm 1.26 & \pm 0.04 & \pm 0.62 \\
\hline$P$ vs. normal & $<0.001$ & N.S. & $<0.001$ & $<0.001$ & $<0.001$ & N.S. & $<0.001$ \\
\hline \multirow[t]{2}{*}{ Osteofibrotic (6) } & 61.18 & 8.60 & 31.88 & $87.90(12.10)$ & 1.91 & 0.69 & 12.98 \\
\hline & \pm 6.78 & \pm 2.98 & \pm 6.17 & \pm 4.39 & \pm 0.65 & \pm 0.29 & \pm 7.47 \\
\hline$P$ vs. normal & $<0.001$ & $<0.001$ & $<0.001$ & N.S. & $<0.001$ & $<0.001$ & $<0.001$ \\
\hline$P$ vs. malacic & $<0.01$ & $<0.05$ & $<0.01$ & $<0.01$ & N.S. & $<0.001$ & $<0.001$ \\
\hline
\end{tabular}

Values are the mean \pm 1 SD. $P$ values are by Student $t$ distribution for grouped data, $P<0.05$ being considered significantly different.

* Length of forming surface per total biopsy area.

$¥$ Rate of bone apposition (width of tetracycline label per day).

$\S$ Rate of bone formation $\left(L_{F} \times R_{B A}\right)$.

Bone hydroxyproline ( $\mathrm{OH}$-proline) was measured by an adaptation of Hosley Olson, Horton, Michelsen, and Atkins' automated analysis of urinary $\mathrm{OH}$-proline (4). The $\mathrm{OH}-$ proline in the bone was released by autoclaving the hydrolysate used for the $\mathrm{Ca}, \mathrm{Mg}$, and $\mathrm{P}$. determinations with an equal amount of $8 \mathrm{~N} \mathrm{HCl}$. An aliquot was titrated with $\mathrm{NaOH}$ to about $\mathrm{pH} 6.0$, with methyl red as an indicator, and diluted to a volume such that $\mathrm{OH}$-proline was in the $0.5-3.0 \mu \mathrm{g} / \mathrm{ml}$ range and the $\mathrm{Cl}$ content was kept below 0.4 $\mathrm{N}$ to prevent color interference. The sensitivity of the AutoAnalyzer method was expanded by changing the sample line to $1.2 \mathrm{~cm}^{3} / \mathrm{min}$, the air line to $0.6 \mathrm{~cm}^{3} / \mathrm{min}$ and replacing the $40-\mathrm{min}$ time delay coil with a cooling-jacketed mixing coil. In our experience the stock $\mathrm{OH}$-proline standard was not stable in $0.001 \mathrm{~N} \mathrm{HCl}$, but was stable for over a $\mathrm{yr}$ at room temperature in $0.5 \mathrm{~N} \mathrm{HCl}$, the diluted standards being neutralized as were the samples. Optical density of the $2.0 \mu \mathrm{g} / \mathrm{ml}$ standard was over 0.3 . Duplicate samples, different determination, varied less than $5 \%$.

Vitamin D treatment and acidosis were studied in two sets of six patients each, a treated set from Vancouver, Canada, and a nontreated set selected from Seattle to match the vitamin $\mathrm{D}$-treated patients by age and duration of disease.

Bone histology was classified as mildly abnormal, osteomalacic, or osteofibrotic on the basis of measurements of total bone area and total bone surface. Area measurements give percent mineralized or osteoid per bone area or per biopsy area. Linear measurements were made of bone perimeter forming, neutral, and resorbing. Tetracycline labeling was used to calculate the rate of bone apposition $\left(R_{B A}\right)^{2}$ in millimeters $\times 10^{-4}$ per day, the length of form-

${ }^{2}$ Abbreviations used in this paper: ACP, amorphous calcium phosphate; $\mathrm{HA}$, crystalline $\mathrm{OH}$-apatite; $\mathrm{L}_{\mathrm{F}}$, length of forming surface; $R_{B A}$, bone apposition rate; $R_{B F}$, bone formation rate.

ing surface $\left(\mathrm{L}_{\mathrm{F}}\right)$ (square millimeters per total biopsy area), and the bone formation rate $\left(\mathrm{R}_{\mathrm{BF}}\right)$ (cubic millimeter $\times 10^{-8}$ per cubic millimeter per day) (5). Histologic results are expressed as the mean \pm 1 SD. $P$ values are by the Student $t$ test, grouped data, $P<0.05$ indicating a significant difference.

\section{RESULTS}

Histological classification of mild, osteomalacic, and osteofibrotic (Table I) was based on the selection of patients with as well-defined a histological type of lesion as possible. Patients were ambulatory and asymptomatic. Normals were volunteers whose ages were between 30 and 60 , roughly the age group of the patients.

The histological study of the normals showed $94.31 \pm$ $7.72 \%$ of the total tissue area mineralized and $5.69 \%$ osteoid, with $18.16 \pm 7.96 \%$ of the bone perimeter forming, $4.03 \pm 1.98 \%$ resorbing, and $77.80 \pm 8.20 \%$ neutral. $R_{\mathbf{B A}}$ by tetracycline labeling was $3.04 \pm 0.79 \mathrm{~mm} \times 10^{-4}$ / day, while the LF (forming perimeter per total area) was $0.52 \pm 0.20 \mathrm{~mm}^{2} / \mathrm{mm}^{3}$. The $R_{\mathbf{B}}$ times $L_{\boldsymbol{F}}$ was the $R_{B F}$ and was $1.50 \pm 0.62 \mathrm{~mm}^{3} \times 10^{-8} / \mathrm{mm}^{3} /$ day for normals.

The mild lesion (10 patients) was characterized by a significant increase in percent of forming perimeter, $34.77 \pm 9.90 \%, P<0.001$, a consequent decrease in neutral, $59.55 \pm 10.57 \%, P<0.001$, with a marginal increase in resorbing, $5.66 \pm 1.75 \%, P<0.05$, and no change in the mineralized-osteoid percentage of total tissue area, $93.70 \pm 2.02 \%-6.30 \%$. The $R_{B A}$ was normal, $2.78 \pm 0.81$, but the greater LF, $1.02 \pm 0.25, P<0.001$, 
resulted in a significant increase in $\mathrm{R}_{\mathrm{BF}}, 2.87 \pm 1.13, P<$ 0.001 .

In osteomalacia (eight patients) the most characteristic change was a large increase in osteoid, $32.41 \%$, with concomitant decrease in percent tissue area mineralized, $67.59 \pm 16.52 \%, P<0.001$. This change was reflected in increased forming perimeter, 76.68 $\pm 9.80 \%$, $P<0.001$, and decreased neutral, $17.76 \pm 9.30 \%, P<$ 0.001 , with no change in the resorbing, $5.55 \pm 2.02 \%$. $\mathrm{R}_{\mathrm{BA}}$ decreased significantly, $1.08 \pm 0.45, P<0.001$, but the marked increase in $\mathrm{LF}, 3.04 \pm 1.26, P<0.001$, resulted in an increased $R_{\mathbf{B F}}, 3.31 \pm 0.62, P<0.001$.

The fibrotic lesion (six patients) showed very different changes. The percent perimeter forming was increased about midway between the mild and malacic lesion, $61.18 \pm 6.78 \%, P<0.001$. However, the resorbing perimeter was also increased, $8.60 \pm 2.98 \%, P<$ 0.001 . These histologic observations were confirmed by measurement of bone formation. The $L_{F}$ was increased, $1.91 \pm 0.65, P<0.001$, as was the $\mathrm{R}_{\mathrm{BA}}, 6.90 \pm 2.94, P<$ 0.001 . These increases resulted in a marked increase in $\mathrm{R}_{\mathbf{B F}}$ to $12.98 \pm 7.47, P<0.001$, as compared to normal or osteomalacic rates.

Many chemical parameters were tested and correlations sought because the iliac crest biopsy presents problems not found in pure cortical bone. Depth of cortex varies greatly along the iliac crest so that the ratio of cortical to spicular bone in a biopsy depends much more on location than on state of disease. Therefore, wherever possible, ratios of related measurements were used rather than relationship by weight or volume, for the latter is often disproportionately affected by varying cortical-spicular combinations. For example, between varying cortical-spicular biopsies from the same normal individual, a $7-8 \%$ variation in $\mathrm{CO}_{3} / \mathrm{g}$ will drop to $1-2 \%$ as $\mathrm{CO}_{3} / \mathrm{Ca} ;$ a $9-10 \% \mathrm{Mg} / \mathrm{g}$ variation will drop to $3 \%$ as $\mathrm{Mg} / \mathrm{Ca}$. Calcium and phosphorus were compared by weight, volume, and $\mathrm{OH}$ proline. No reference base is superior to weight, the variance being about $5 \%$. The $\mathrm{Ca} / \mathrm{P}$ ratio, on the other hand, varies only about $1 \%$. OH-proline, representing collagen matrix, is constant throughout the biopsy and therefore relates better to true volume than to weight, reducing a $6 \%$ variance to $2 \%$.

Of the many chemical parameters studied, the only consistent abnormalities found for the histological classes were a decrease of bone carbonate and an increase in bone magnesium (Table II, Fig. 1). Bone $\mathrm{CO}_{3}$ (meq/g) decreased from a normal of $1.589 \pm 0.178$ to $1.417 \pm$ $0.177, P<0.02$, for the mild lesion; $1.360 \pm 0.137$, $P<0.01$, for the malacic; and 1.104 $\pm 0.217, P<0.001$, for the fibrotic. The more consistent $\mathrm{CO}_{3} / \mathrm{Ca}$ ratio decreased from $166.9 \pm 7.8 \times 10^{-8}$ for normals to $141.1 \pm 12.6 \times 10^{-3}, \quad P<0.001$, for mild; $145.5 \pm 16.0$ $\times 10^{-3}, \quad P<0.001$, for malacic; and $126.3 \pm 12.3 \times$ $10^{-3}, P<0.001$, for fibrotic. Bone $\mathrm{Mg}$ (meq/g) increased from a normal of $0.1798 \pm 0.0258$ to $0.2497 \pm 0.0282, P<$ 0.001 , for the mild; $0.2486 \pm 0.0410, P<0.001$, for the osteomalacic; and $0.3101 \pm 0.0543, P<0.001$, for the osteofibrotic. With the $\mathrm{Mg} / \mathrm{Ca}$ ratio, the normal of $19.00 \pm 2.93 \times 10^{-3}$ increased to $25.02 \pm 3.47 \times 10^{-3}, P<$ 0.001 , in mild disease; $28.00 \pm 5.48 \times 10^{-3}, P<0.001$, in osteomalacia; and $36.18 \pm 4.42 \times 10^{-3}, \quad P<0.001$, in osteofibrosis. Both abnormalities were so much greater in osteofibrosis than in osteomalacia that a statistical difference exists between the two, $P<0.05$ for the decrease in $\mathrm{CO}_{3} / \mathrm{Ca}$ or $P<0.02$ for the increase in $\mathrm{Mg} / \mathrm{Ca}$.

After true density measurements were begun, 11 patients with mild disease, 6 with osteomalacia, and 10 with osteofibrosis were identified histologically. The

TABLE II

Chemical Parameters of Human Iliac Crest Biopsies Grouped by Histological Classification

\begin{tabular}{|c|c|c|c|c|c|c|c|c|c|}
\hline $\begin{array}{l}\text { Histological } \\
\text { class (n) }\end{array}$ & $\mathrm{CO}_{3}$ & $\mathrm{CO}_{3} / \mathrm{Ca}$ & $\mathrm{Ca}$ & $\mathrm{PO}_{4}$ & $\mathrm{Ca} / \mathrm{P}$ & $\mathbf{M g}$ & $\mathrm{Mg} / \mathrm{Ca}$ & OH-P & $\mathrm{Na}$ \\
\hline & $m e q / g$ & & $m e q / g$ & $m e q / g$ & $\mathrm{mmol} / \mathrm{mmol}$ & $m e q / g$ & & $\mathrm{mmol} / \mathrm{g}$ & $m e q / g$ \\
\hline \multirow[t]{2}{*}{ Normal (19) } & 1.539 & 0.1669 & 9.507 & 8.283 & 1.720 & 0.1798 & 0.01900 & 0.2862 & 0.2911 \\
\hline & \pm 0.178 & \pm 0.0078 & \pm 0.860 & \pm 0.736 & \pm 0.077 & \pm 0.0258 & \pm 0.00293 & \pm 0.0356 & \pm 0.0120 \\
\hline \multirow[t]{2}{*}{ Mild (10) } & 1.417 & 0.1411 & 10.020 & 8.604 & 1.746 & 0.2497 & 0.02502 & 0.2786 & 0.3007 \\
\hline & \pm 0.177 & \pm 0.0126 & \pm 0.569 & \pm 0.450 & \pm 0.035 & \pm 0.0282 & \pm 0.00347 & \pm 0.0145 & \pm 0.0153 \\
\hline$P$ vs. normal & $<0.02$ & $<0.001$ & NS & NS & NS & $<0.001$ & $<0.001$ & NS & NS \\
\hline \multirow[t]{2}{*}{ Osteomalacic (8) } & 1.360 & 0.1455 & 9.249 & 8.083 & 1.709 & 0.2486 & 0.02800 & 0.2889 & 0.2945 \\
\hline & \pm 0.137 & \pm 0.0160 & \pm 0.567 & \pm 0.377 & \pm 0.052 & \pm 0.0410 & \pm 0.00548 & \pm 0.0322 & \pm 0.0286 \\
\hline$P$ vs. normal & $<0.01$ & $<0.001$ & NS & NS & NS & $<0.001$ & $<0.001$ & NS & NS \\
\hline \multirow[t]{2}{*}{ Osteofibrotic (6) } & 1.086 & 0.1263 & 8.624 & 7.414 & 1.738 & 0.3101 & 0.03618 & 0.3094 & 0.2817 \\
\hline & \pm 0.189 & \pm 0.0123 & \pm 1.431 & \pm 0.888 & \pm 0.104 & \pm 0.0543 & \pm 0.00442 & \pm 0.0412 & \pm 0.0178 \\
\hline$P$ vs. normal & $<0.001$ & $<0.001$ & NS & $<0.05$ & NS & $<0.001$ & $<0.001$ & NS & NS \\
\hline$P$ vs. mild & $<0.01$ & $<0.02$ & $<0.02$ & $<0.01$ & NS & $<0.02$ & $<0.001$ & $<0.05$ & $<0.05$ \\
\hline$P$ vs. malacic & $<0.02$ & $<0.05$ & NS & NS & NS & $<0.05$ & $<0.02$ & NS & NS \\
\hline
\end{tabular}

Values are the mean $\pm 1 \mathrm{SD}$. $P$ values are by the Student $t$ test, grouped data, $P<0.05$ indicating a significant difference. Weight values are per gram air dried, fat-free, powdered bone. 
true density of the air-stable, defatted bone was found to be $1.976 \pm 0.068$ for 12 normals with a C.V. of $3.4 \%$. Patients with mild disease showed a density of $1.916 \pm$ 0.084 , C.V. $4.4 \%$, while the density of osteomalacia was $1.961 \pm 0.050$, C.V. $2.5 \%$. The fibrotic lesion was associated with a density of $1.897 \pm 0.035$, C.V. $3.4 \%$, significantly decreased from normal, $P<0.01$, and also from the malacic group, $P<0.01$ (Fig. 2).

Table III shows the results of the chemical and histological studies of iliac crest biopsies from a set of six vitamin D-treated dialysis patients from Vancouver, Canada, and a comparable set, by age and duration of dialysis, of nontreated patients from Seattle. Dialysate concentrations and total hours of dialysis were the same, but in the Seattle patients dialysis was performed three times weekly, while the Vancouver patients dialyzed twice weekly, resulting in a lower ongoing serum $\mathrm{HCO}_{3}^{-}$ level, $18.0 \pm 1.5$ vs $23.0 \pm 1.7, P<0.01$.

The vitamin $D$-treated patients showed a decrease in osteoid, $9.00 \pm 5.5 \%$ vs. $16.4 \pm 9.6 \%, P<0.02$, with a concomitant increase in the percent bone mineralized. There was a decrease in the percent bone perimeter forming, $38.3 \pm 14.2 \%$ vs $65.7 \pm 11.1 \%, P<0.001$. Bone resorption by percent perimeter showed no change.

The chemical measurements showed a slight increase in bone calcium per gram, approaching significance for the vitamin D-treated patients. There was a decrease in

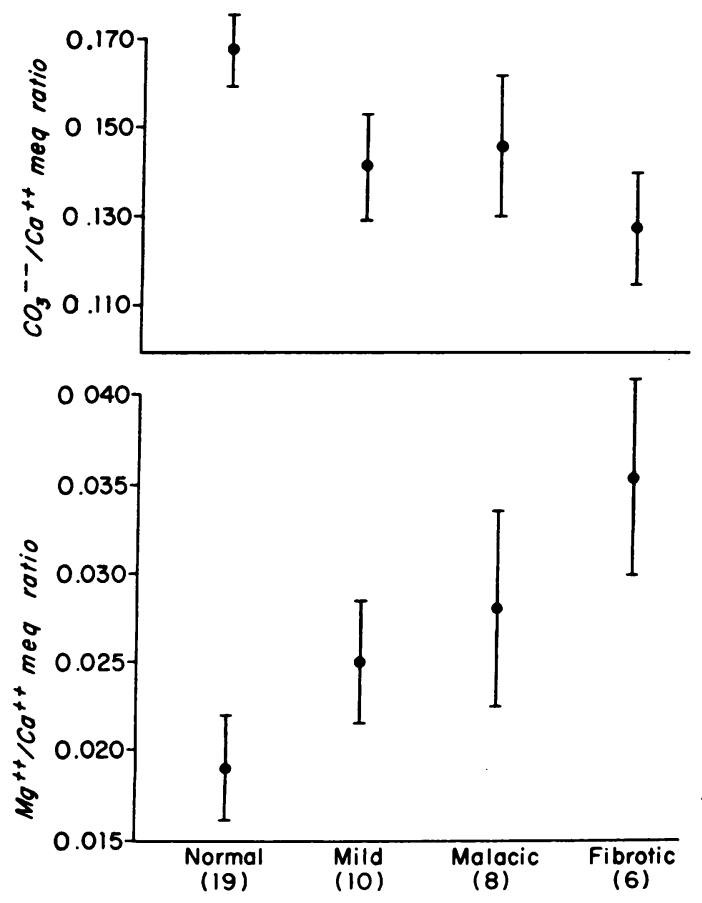

Figure 1 Comparison of $\mathrm{CO}_{3} / \mathrm{Ca}$ and $\mathrm{Mg} / \mathrm{Ca}$ ratios in patients with mild, osteomalacic, and osteofibrotic renal osteodystrophy. Figures signify the mean $\pm 1 \mathrm{SD}$.

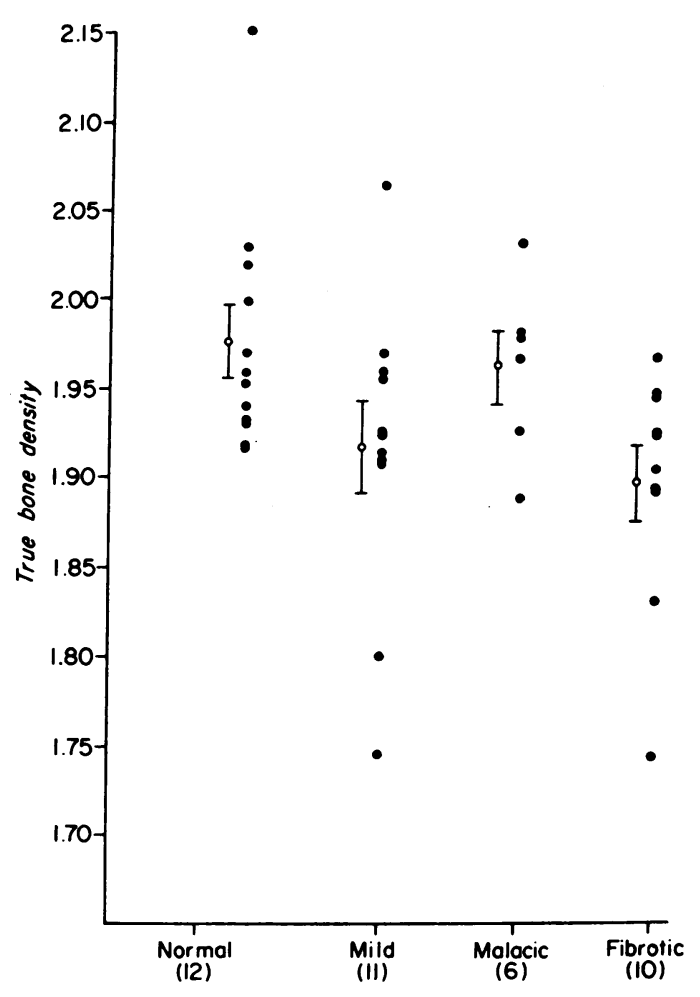

Figure 2 Comparison of true bone density in patients with mild, osteomalacic, and osteofibrotic renal osteodystrophy. Figures signify the mean $\pm 1 \mathrm{SD}$.

$\mathrm{OH}$-proline per gram of the same significance, which is probably only the reflection of the additional weight per biopsy unit. The only significant difference is an increase in the $\mathrm{Ca} / \mathrm{P}$ ratio for the patients under vitamin $\mathrm{D}$ treatment, $1.804 \pm 0.040$ vs $1.683 \pm 0.093, P<0.02$, for the untreated set. Bone sodium, carbonate, and magnesium were also measured but showed no differences.

\section{DISCUSSION}

The normal process of bone maturation involves the cellular elaboration of amorphous calcium phosphate (ACP), which is metastable in relation to crystalline $\mathrm{OH}$-apatite (HA) (6). Transformation of ACP to HA progresses with age. In growing rat bone, a $70 \%$ ratio of $\mathrm{ACP}$ to $\mathrm{HA}$ at 8 days decreases to approximately $36 \% \mathrm{ACP}$ at 60 days and thereafter (7). This declining ratio of $\mathrm{ACP}$ to $\mathrm{HA}$ is also characterized by an increasing $\mathrm{Ca} / \mathrm{P}$ ratio $(7)$ and an increased bone density $(8,9)$. The physical characteristics of this maturation process result in a progressive increase in crystal surface fluid interface because HA crystals are needle-shaped in contrast to the spherical shape of ACP (10), and because the mean crystal size increases until 40 days of age (11). Comparison by gas absorption of the surface area of ACP to that of HA reveals that the 
TABLE III

Histological and Chemical Measurements of Iliac Crest Biopsies of Vit. D-Treated and Untreated Dialysis Patients

\begin{tabular}{|c|c|c|c|c|c|}
\hline \multirow[b]{2}{*}{ Parameter } & \multicolumn{2}{|c|}{$\begin{array}{l}\text { Vitamin D-treated } \\
(\mathrm{n}=6)\end{array}$} & \multicolumn{2}{|c|}{$\begin{array}{l}\text { Untreated } \\
(n=6)\end{array}$} & \multirow[b]{2}{*}{$p$ value } \\
\hline & Mean & SD & Mean & SD & \\
\hline Bone mineralized, $\%$ & 91.0 & \pm 5.5 & 83.6 & \pm 9.6 & $<0.02$ \\
\hline osteoid, $\%$ & 9.0 & \pm 5.5 & 16.4 & \pm 9.6 & $<0.02$ \\
\hline Bone perimeter, forming, $\%$ & 38.3 & \pm 14.2 & 65.7 & \pm 11.1 & $<0.001$ \\
\hline resorbing, $\%$ & 8.5 & \pm 1.9 & 7.4 & \pm 23 & NS \\
\hline $\mathrm{R}_{\mathrm{BF}} m m^{3} / m m^{3} \times 10^{-8}$ & 4.0 & \pm 4.4 & 12.4 & \pm 9.9 & NS \\
\hline Bone calcium, $m e q / g$ & 9.650 & \pm 1.016 & 8.390 & \pm 1.275 & $\mathrm{NS}(<0.10)$ \\
\hline Phosphate, $m e q / g$ & 8.010 & \pm 0.697 & 7.389 & \pm 0.884 & NS \\
\hline $\mathrm{Ca} / \mathrm{P}$ molar ratio & 1.804 & \pm 0.040 & 1.683 & \pm 0.093 & $<0.02$ \\
\hline Carbonate, $m e q / g$ & 1.342 & \pm 0.153 & 1.193 & \pm 0.277 & NS \\
\hline $\mathrm{CO}_{3} / \mathrm{Ca}$ ratio & 0.139 & \pm 0.005 & 0.141 & \pm 0.018 & NS \\
\hline Magnesium, meq/g & 0.290 & \pm 0.046 & 0.294 & \pm 0.059 & NS \\
\hline $\mathrm{Mg} / \mathrm{Ca}$ ratio & 0.030 & \pm 0.0025 & 0.0353 & \pm 0.0059 & NS $(<0.10)$ \\
\hline Sodium, $m e q / g$ & 0.283 & \pm 0.015 & 0.278 & \pm 0.016 & NS \\
\hline OH-Proline, $\mathrm{mmol} / \mathrm{g}$ & 0.275 & \pm 0.018 & 0.312 & \pm 0.041 & $\mathrm{NS}(<0.10)$ \\
\hline Serum bicarbonate, meq/liter & 18.0 & \pm 1.5 & 23.0 & \pm 1.7 & $<0.01$ \\
\hline
\end{tabular}

Patients were matched by age and duration of dialysis.

HA has 2-4 times the surface area, reflecting differences in geometry and particle size (12).

Coincident with bone crystal maturation is the cellular elaboration of collagen. This collagen matrix has decreased solubility as it becomes mineralized $(13,14)$.

While there is presently no direct evidence regarding the carbonate content of $\mathrm{ACP}$, indirect evidence implies that a higher ratio of $\mathrm{ACP}$ to $\mathrm{HA}$ is associated with a decrease in carbonate content. As previously noted, the normal aging process is associated with decreasing $\mathrm{ACP}$ and increasing $\mathrm{HA}$. In studies of mineral maturation in the chick embryo, a corresponding progressive increase was seen in bone carbonate from 0.6 $\mathrm{mmol} / \mathrm{g}$ ash at 9 days to $1.38 \mathrm{mmol} / \mathrm{g}$ ash at six mo (15).

Magnesium is known to stabilize ACP and to inhibit the formation of HA in vitro (16). Perhaps more important to the interpretation of the increased $\mathrm{Mg}$ herein reported is that it has been found to be surface-located in relation to crystal lattice (17). $\mathrm{Mg}$ content has not been studied as a function of bone maturation.

In the uremic state there is considerable evidence of altered bone metabolism. In in vitro studies of bone from patients with uremia, increased $\mathrm{O}_{2}$ uptake, lactate production, and bone formation resorption have been observed (18). In rats with chronic renal insufficiency a maturational defect has been characterized as an increase in soluble collagen and a decrease in bone density $(1,2)$. In sturlies of human necropsy material, decreased bone carbonate (19), $\mathrm{Ca} / \mathrm{P}$ ratio $(19,20)$, and decreased bone density (19) have been reported. Since the advent of atomic absorption, increased $\mathrm{Mg}$ has been reported in necropsy material $(21,22)$, but contrary to our findings, normal $\mathrm{Mg}$ has been reported in biopsy material (23).

It thus appears that in necropsy material (19), and now in our biopsy material, a progression of renal osteodystrophy is associated with decreasing carbonate content. This information does not imply that the complexity of the bone carbonate decrease is resolved. For many years it has been known that acidosis can reduce bone carbonate $(24,25)$. Bone carbonate can decrease $1.5 \%$ in $6 \mathrm{~h}$ with an acute acid load..$^{8}$ This decrease is entirely as sodium carbonate. In dogs rendered acidotic for 5-10 days there is a $7 \%$ decrease in bone carbonate. Approximately $80 \%$ of this carbonate decrease is in excess of $\mathrm{Na}$ (3) and is presumably associated with calcium as judged by calciuresis (26). It is now also clear that progression of renal osteodystrophy from the minimal lesion to osteofibrosis is associated with a progressive decline in bone carbonate. Yet from the observations herein reported, more acidotic dialysis patients on chronic maintenance hemodialysis did not manifest greater decreases in bone carbonate than did mildly acidotic patients.

With regard to bone $\mathrm{Mg}$ there appears to be even

${ }^{3}$ Burnell, J. M., and E. Teubner. The distribution of infused mineral acid in the dog. Manuscript in preparation. 
greater uncertainty. It is clear that an increase in $\mathrm{Mg}$ is present in patients with minimal morphologic bone change and is greatly increased in osteofibrosis. It is tempting to consider the possibility that the presence of increased bone $\mathrm{Mg}$ contributes to the maturational defect because of its known capability of increasing the stability of ACP and inhibiting the formation of crystalline apatite (16). However, such a postulate permits no reasonable explanation for the presence of the increased $\mathrm{Mg}$. It seems more likely that events at the cellular level result in increased metabolic activity and increased bone turnover, resulting in an increased ACP and decreased apatite crystals, probably of smaller size. Thus, if $\mathrm{Mg}$ is surface-located in the lattice, these events would result in the presence of higher $\mathrm{Mg} / \mathrm{Ca}$ ratios. The inverse relationship of $\mathrm{Mg}$ and $\mathrm{CO}_{3}$ content observed in the present study (Fig. 1) might be interpreted as having a common etiology. However, this inverse relationship does not always exist, as evidenced by the fact that in the dogs rendered acidotic for 7-10 days we failed to find in retrospective analysis any increase in $\mathrm{Mg}$ (3), although the bone carbonate was decreased $7 \%$.

The finding of a decreased density in osteofibrosis may well reflect the increased ACP-HA ratio seen in less mature bone $(2,8,9)$; however, some caution must be observed. An alternative could be that increased fibrous tissue in the marrow spaces of the osteofibrotic set could increase the true volume, particularly by replacing lipid, thereby decreasing density.

The data herein reported would appear to identify in human biopsy material the existence of a maturational defect previously found only in growing rats (2). These data extend the characterization of the maturational defect to include a decrease in carbonate and an increase in magnesium. The $\mathrm{Mg}$ increase could be solely the consequence of the presumed increase in surface area; however, the only evidence for such a speculation is its known concentration in the hydration shell around apatite crystals (17).

The histologic correlation with the maturational defect appears to be good. The lesser increases in $R_{\mathbf{B F}}$ and resorption seen in the mild lesion are associated with smaller changes in bone $\mathrm{CO}_{3}$ and $\mathrm{Mg}$. The very high $\mathrm{R}_{\mathbf{B F}}$ and resorption seen in osteofibrosis are associated with the most severe alteration of bone $\mathrm{CO}_{3}$ and $\mathrm{Mg}$ and with a reduction in bone density.

Evidence as to the role of vitamin $\mathrm{D}$ deficiency in production of the maturational defect is conflicting. In rats fed a diet deficient in vitamin $\mathrm{D}$ the ACP content is increased and $\mathrm{Ca} / \mathrm{P}$ ratio decreased (6). Yet in studies in uremic rats vitamin $\mathrm{D}$ therapy failed to influence the maturational defect (2), while in our biopsy data vitamin $\mathrm{D}$ therapy appeared to increase $\mathrm{Ca} / \mathrm{P}$ ratios, but did not influence bone $\mathrm{CO}_{3}$ or $\mathrm{Mg}$.
The remaining known factor in renal osteodystrophy is hyperparathyroidism. The correlation of osteofibrosis with both hyperparathyroidism (27) and with the severity of the maturational defect is striking. Also, it seems likely that all of our patients have hyperparathyroidism $(28,29)$. However, the question of whether the maturational defect described in rats $(1,2)$ and now in humans can be ascribed solely to hyperparathyroidism must remain unanswered at present. A possible alternative or additional factor from the accumulation of uremic toxins may well have as yet undescribed effects on bone cellular metabolism.

\section{ACKNOWLEDGMENTS}

We wish to acknowledge our indebtedness to Dr. David J. Baylink, in whose laboratory Dr. Norma Mahoney performed the histological classifications, and to Dr. E. C. Cameron, University of British Columbia, for providing access to patients treated with vitamin D.

This work was supported in part by National Institutes of Health contract NIH 71-2486 and National Institutes of Health grant AM-09096.

\section{REFERENCES}

1. Hahn, T. J., and L. V. Avioli. 1970. Effect of chronic uremia on collagen metabolism in skin and bone. Arch. Intern. Med. 126: 882.

2. Russell, J. E., and L. V. Avioli. 1972. Effect of experimental chronic renal insufficiency on bone mineral and collagen maturation. J. Clin. Invest. 51: 3072.

3. Burnell, J. M. 1971. Changes in bone sodium and carbonate in metabolic acidosis and alkalosis in the dog. J. Clin. Invest. 50: 327.

4. Hosley, H. F., K. B. Olson, J. Horton, R. Michelsen, and R. Atkins. 1969. Automated analysis of urinary hydroxyproline for cancer research. In Advances in Automated Analysis. Technicon International Congress. Mediad Incorporated, White Plains, N. Y. 1: 105.

5. Frost, H. M. 1969. Tetracycline-based histological analysis of bone remodeling. Calcif. Tissue Res. 3: 211.

6. Termine, J. D., and A. S. Posner. 1967. Amorphous/ crystalline interrelationships in bone mineral. Calcif. Tissue Res. $1: 8$.

7. Termine, J. D., and A. S. Posner. 1966. Infrared analysis of rat bone: age dependency of amorphous and crystalline mineral fractions. Science (Wash. D. C.). 153: 1523.

8. Quinaux, N., and L. J. Richelle. 1967. X-ray diffraction and infrared analysis of bone specific gravity fractions in the growing rat. Isr. J. Med. Sci. 3: 677.

9. Bonucci, E., A. Ascenzi, F. Vittur, M. C. Pugliarello, and B. de Benard. 1970. Density of osteoid tissue and osteones at different degree of calcification. Calcif. Tissue Res. 5: 100.

10. Molnar, Z. 1959. Development of the parietal bone of young mice. I. Crystals of bone mineral in frozendried preparations. J. Ultrastruct. Res. 3: 39.

11. Menczel, J., A. S. Posner, and R. A. Harper. 1965. Age changes in the crystallinity of rat bone apatite. Isr. J. Med.Sci. $1: 251$.

12. Holmes, J. M., and R. A. Beebe. 1971. Surface areas by gas adsorption on amorphous calcium phosphate and crystalline hydroxyapatite. Calcif. Tissue Res. 7: 163. 
13. Jackson, D. S., and J. P. Bentley. 1960. On the significance of the extractable collagens. J. Biophys. Biochem. Cytol. $7: 37$.

14. Mills, B. G., and L. A. Bavett. 1968. Bone collagen dynamics. Clin. Orthop. Related Res. $57: 267$.

15. Pellegrino, E. D., and R. M. Biltz. 1972. Mineralization in the chick embryo. I. Monohydrogen phosphate and carbonate relationships during maturation of the bone crystal complex. Calcif. Tissue Res. 10: 128.

16. Bachra, B. N., O. R. Trautz, and S. L. Simon. 1965. Precipitation of calcium carbonates and phosphates. III. The effect of magnesium and fluoride ions on the spontaneous precipitation of calcium carbonates and phosphates. Arch. Oral Biol. 10: 731.

17. Neuman, W. F., and B. J. Mulryan. 1971. Synthetic hydroxyapatite crystals. IV. Magnesium incorporation. Calcif. Tissue Res. 7 : 133.

18. Nichols, G. Jr., B. Flanagan, J. van der Sluys Veer, J. W. Johnson, C. L. Hampers, and J. P. Merrill. 1972. Metabolic studies of bone in uremia before and after treatment. Metab. (Clin. Exp.) 21: 317.

19. Pellegrino, E. D., and R. M. Biltz. 1965. The composition of human bone in uremia. Observations on the reservoir functions of bone and demonstration of a labile fraction of bone carbonate. Medicine (Baltimore). 44: 397.

20. Kaye, M. 1964. Mineral analysis of the fourth lumbar vertebra in health and renal failure. J. Clin. Invest. 43: 1367.
21. Contiguglia, S. R., A. C. Alfrey, N. Miller, and D. Butkus. 1972. Total-body magnesium excess in chronic renal failure. Lancet. $1: 1300$.

22. Berlyne, G. M., J. Ben-Air, J. Szwarcberg, J. Kaneti, G. M. Danovitch, and M. Kaye. 1972. Increase in bone magnesium content in renal failure in man. Nephron. 9: 90 .

23. Lim, P., and E. Jacob. 1972. Magnesium status in chronic uraemic patients. Nephron. 9: 300

24. Goto, K. 1918. Mineral metabolism in experimental acidosis. J. Biol. Chem. $36: 355$.

25. Irving, L., and A. L. Chute. 1932. The participation of the carbonates of bone in the neutralization of ingested acid. J. Cell. Comp. Physiol. 2: 157.

26. Lemann, J. Jr., J. R. Litzow, and E. J. Lennon. 1966. The effects of chronic acid loads in normal man: further evidence for the participation of bone mineral in the defense against chronic metabolic acidosis. $J$. Clin. Invest. 45 : 1608.

27. Stanbury, S. W. 1957. Azotaemic renal osteodystrophy. Br. Med. Bull. 13: 57.

28. Berson, S. A., and R. S. Yalow. 1966. Parathyroid hormone in plasma in adenomatous hyperparathyroidism, uremia, and bronchogenic carcinoma. Science (Wash. D. C.). 154 : 907.

29. Reiss, E., J. M. Canterbury, and A. Kanter. 1969. Circulating parathyroid hormone concentration in chronic renal insufficiency. Arch. Intern. Med. $124: 417$. 